\title{
Article \\ UV Curable Coatings Based on Urethane Acrylates Containing Eugenol and Evaluation of Their Antimicrobial Activity
}

\author{
Paulina Bednarczyk 1,*(D), Agnieszka Wróblewska 2,*iD, Agata Markowska-Szczupak ${ }^{3}$, \\ Paula Ossowicz-Rupniewska ${ }^{1}$ D , Małgorzata Nowak ${ }^{1}$, Marcin Kujbida ${ }^{2}$ D, Adrianna Kamińska ${ }^{2}$ \\ and Zbigniew Czech ${ }^{1}$
}

1 Department of Organic Chemical Technology and Polymer Materials, Faculty of Chemical Technology and Engineering, West Pomeranian University of Technology in Szczecin, 70-322 Szczecin, Poland; Paula.Ossowicz@zut.edu.pl (P.O.-R.); malgorzata.nowak@zut.edu.pl (M.N.); Zbigniew.Czech@zut.edu.pl (Z.C.)

2 Department of Catalytic and Sorbent Materials Engineering, Faculty of Chemical Technology and Engineering, West Pomeranian University of Technology in Szczecin, 71-065 Szczecin, Poland; marcin.kujbida@zut.edu.pl (M.K.); Adrianna.Kaminska@zut.edu.pl (A.K.)

3 Department of Chemical and Process Engineering, Faculty of Chemical Technology and Engineering, West Pomeranian University of Technology in Szczecin, 71-065 Szczecin, Poland; agata.markowska@zut.edu.pl

* Correspondence: paulina.bednarczyk@zut.edu.pl or bednarczyk.pb@gmail.com (P.B.); agnieszka.wroblewska@zut.edu.pl (A.W.)

Citation: Bednarczyk, P.;

Wróblewska, A.;

Markowska-Szczupak, A.;

Ossowicz-Rupniewska, P.; Nowak,

M.; Kujbida, M.; Kamińska, A.; Czech,

Z. UV Curable Coatings Based on

Urethane Acrylates Containing

Eugenol and Evaluation of Their

Antimicrobial Activity. Coatings 2021,

11, 1556. https://doi.org/10.3390/

coatings11121556

Academic Editor: Zao Yi

Received: 3 December 2021

Accepted: 15 December 2021

Published: 17 December 2021

Publisher's Note: MDPI stays neutral with regard to jurisdictional claims in published maps and institutional affiliations.

Copyright: (c) 2021 by the authors. Licensee MDPI, Basel, Switzerland. This article is an open access article distributed under the terms and conditions of the Creative Commons Attribution (CC BY) license (https:// creativecommons.org/licenses/by/ $4.0 /)$.

\begin{abstract}
This work presents studies on the obtaining of UV-curable coatings with antimicrobial activity. Urethane acrylates (UAs) have excellent physicochemical properties including high reactivity in systems with radical photoinitiators in the presence of UV radiation and good balance between hardness and flexibility in the formed coatings. At the same time, eugenol is well known as the compound hindering the growth of various microorganisms. Hence, the materials obtained by the modification of UA resins with eugenol can be used to protect various surfaces, especially against microorganisms. This study aimed to examine the influence of the amount of eugenol on the chemical, physical, thermal, and mechanical properties of the obtained UA coatings and find the conditions at which the optimal properties for industrial applications such coatings can be achieved. These materials were successfully obtained. Taking into account that eugenol is a very cheap reactant, and it can be obtained from natural sources by the simple distillation method, the proposed method combined the good points of obtaining protective coatings by UV curing with the utilization of vegetable, renewable reactants (biomass), such as components giving special properties to these materials, in this case, antimicrobial properties. In this study, photoreactive coatings with antimicrobial properties for the following microorganisms: fungi (C. albicans), Gram-positive bacteria (S. epidermidis) as well as Gram-negative bacteria (E. coli), were obtained. The obtained coatings were cured over a short time. They were colorless and characterized by a wide range of properties and applications.
\end{abstract}

Keywords: urethane acrylates; UV curable coatings; eugenol; antimicrobial activity

\section{Introduction}

Photocurable coatings containing compounds of natural origin (for example, limonene and eugenol) are very attractive intermediates for various applications in green materials chemistry. At present, medical applications for this type of materials are of the greatest interest. Mainly, it is connected with the low toxicity of the final product [1,2]. High-efficiency photocurable coatings are obtained by the photopolymerization reaction. The popularity of UV-driven chemical reactions has grown very significantly in recent years, mainly due to the fact that such reactions allow to obtain a high conversion of a raw material in a very curing short time [3]. This method also does not require the use of solvents, and it consumes little energy, because the reaction is carried out at a low temperature [4-6]. 
The varnishes curable by ultraviolet (UV) are composed of oligomers, monomers, or reactive diluents, photoinitiators, and additives. The physical and tensile properties of the obtained polymeric films depended on the coating formulation and the type of radiation used $[7,8]$. The urethane acrylate oligomer was used as the film former, and it is usually composed of highly viscous resins [9-11]. The monomer is added to these polymers to blend other ingredients and control the formulation viscosity (the reactive diluent). Still, it affects both the cure speed and the polymerization extent, as well as the properties of the cured film $[12,13]$. In addition, the varnish includes the radical photoinitiator that initiates the polymerization reaction [14-17].

Urethane acrylates possess the best balance between hardness, toughness, and chemical and abrasion resistance on the one hand, and flexibility and elasticity on the other. Possibilities of changeability are generally very vast so that the tough and abrasion-resistant films can be produced as well as the incredibly soft and elastic ones. Many of these properties are based on the ability of urethane groups to form the intermolecular hydrogen bonds, which, however, simultaneously increase the viscosity of the formulation [18]. If the properties of the films were the sole consideration, urethane acrylates would undoubtedly be the most frequently used oligomers in the radiation-curable formulations. However, the high viscosity significantly reduces the range of opportunities for their widespread use. In view of this fact, in this publication, we used the reactive diluent in the form of a trifunctional acrylate monomer $[19,20]$. The most reactive systems are composed of aliphatic urethane with the high functionality and low viscosity. This class of oligomers produces the films with the highest quality. Properties such as adhesion, hardness, and abrasionresistant combined with high elasticity and flexibility are excellent, the same as resistance to weathering and yellowing. As a result of these outstanding properties, approximately $80 \%$ of the urethane acrylates are based on aliphatics [18]. Poly(urethane acrylates) copolymers are prepared directly from the monomers by the photopolymerization. The obtained copolymers may be used as the active environment for the later radical copolymerization initiated by the UV radiation [21]. As a result of the photochemically initiated reaction of the dissociation of the double bonds of acrylate groups, the curing of the polymer coating is observed.

Today, essential oils enjoy great interest and are widely used in medicine, in the perfume industry, in cosmetics, in the food industry, in organic syntheses, and in the production of polymeric materials. For example, an orange oil obtained from orange peels, containing $98 \%$ of limonene, was used in the production of photocurable varnishes. This application of limonene was described in our previous work [22] in which we obtained photocurable varnishes with pleasant smells that showed the bactericidal and biostatic properties. Another compound of natural origin that is currently of great interest to researchers is eugenol. It is the main component of the clove essential oil, which is isolated from flower buds of Syzygium aromaticum (family: Myrtaceae). Many medical applications described for this essential oil is connected with the presence of eugenol in its composition [23-28]. Eugenol (4-allyl-2-methoxyphenol) can be used for example as the antiseptic agent in dental and medical practice $[23,27,29]$. Eugenol is the aromatic compound that is more complex taking into account its structure than limonene. In addition to the allylic group, the eugenol molecule also has the hydroxyl and methoxy groups attached to the aromatic ring. The limonene molecule has the different, cyclic but not aromatic structure. In the side chain there is one double bond in the limonene molecule, while the other occurs in the cyclic ring. Thus, application of eugenol in the production of photocurable varnishes can cause formation of a product with different properties than the varnishes obtained with limonene molecules.

In this work the preparation of the urethane acrylate resin modified with the different amounts of eugenol was reported. For the preparation of the photoreactive coating compositions the radical photoinitiator was also used. The coatings were created with the use of the UV radiation. The obtained materials were tested for the kinetics of the photopolymerization process and the properties of the cured coatings. The studies also focused on testing 
the antimicrobial activity of the obtained photocurable UA coatings, particularly against Gram-negative and Gram-positive bacteria (Escherichia coli and Staphylococcus epidermidis) as well as the representative of the yeastlike fungus (Candida albicans). This work aimed to examine the influence of the eugenol molecules concentration on the chemical, physical, thermal, and mechanical properties and antimicrobial properties of the obtained coatings. In addition, the aim was to find such conditions at which the optimal properties for industrial applications could the prepared coatings be achieved. Coatings of this type are suitable for high-grade exterior applications due to the fact of their resistance to weathering and yellowing. Above all, they could be used to protect a substrate against microorganisms. They can be applied to all potential substrates such as plastics, metal, wood, paper, textiles, and leather [18]. Considering the properties of the used biologically active compound (eugenol), these coatings can find applications in the furniture industry, for production of everyday objects, and they can also find special applications, e.g., in medicine and in the cosmetics industry.

\section{Materials and Methods}

\subsection{Materials}

The following raw materials were used for the studies: aliphatic urethane acrylate (Genomer 4425, Rahn, Zurich, Switzerlandt), 1-hydroxycyclohexyl phenyl ketone (Irgacure 184, BASF, Ludwigshafen, Germany), trimethylolpropane triacrylate as a reactive diluent (TMPTA, BASF), and eugenol (>98\%, Sigma, Buchs, Switzerland).

\subsection{Preparation of Coatings}

The preparation of the photocurable urethane acrylate coatings with the different amounts of the unsaturated biologically active compound (eugenol) allowed for the obtention of the hybrid polymer with help of the photochemically initiated reaction. For this purpose, coating compositions were prepared by homogenization (using a mechanical homogenizer) the resin and eugenol (in the concentration of 1-10 $\mathrm{wt} \%$, thus reducing the proportion of UA resin) at the ambient temperature and under dark conditions. In the next stage, the photoinitiator ( $3 \mathrm{wt} \%$ in relation to the photoreactive mixture with eugenol) was mixed with the reactive acrylic diluent (TMPTA $10 \mathrm{wt} \%$ ), until the homogenous solution was obtained. Thus, the names of the photoreactive systems were PRE0 for the non-eugenol system, PRE1 for the $1 \mathrm{wt} \%$ eugenol system, etc. Subsequently, the curing solution was applied to the glass substrates by means of a gap applicator $(120 \mu \mathrm{m})$. The polymeric film was cured under a light source for $120 \mathrm{~s}$ and with an intensity of $10 \mathrm{~mW} / \mathrm{cm}^{2}$. The distance from the UV source $(\lambda=350-400 \mathrm{~nm}, 36 \mathrm{~W})$ to the photoreactive cure layer was $5 \mathrm{~cm}$. The way of the preparation of the photocurable urethane acrylate coatings containing eugenol applied in our work was presented in Figure 1.

\subsection{Spectroscopy}

The Fourier-transformed infrared (FTIR) spectroscopy in the attenuated total reflectance mode (ATR) was measured on an Nicolet iS5 instrument (Thermo Electron Corporation, Waltham, MA, USA). Sixteen scans were averaged for each sample in the range of $4000-400 \mathrm{~cm}^{-1}$ at the room temperature. The infrared spectrums were used to characterize the obtained UA with the different amounts of eugenol. In addition, the series real-time IR (RT-IR) were used to determine the conversion of the unsaturated chemical bonds. More importantly, this spectroscopic technique permits in situ monitoring of the chemical processes via mimicking the disappearance of the characteristic bands of the reactive compounds subjected to UV exposure. The photoreactive mixture was placed in the mold made from glass slides and spacers of $15 \mathrm{~mm}$ in diameter and 0.5 in thickness. The samples were placed in the compartment of the Fourier transform infrared spectrometer and were simultaneously exposed to the UV radiation source (mercury UV lamp, Indigo, Łódź, Poland, $36 \mathrm{~W}, 280-400 \mathrm{~nm}, 10 \mathrm{~mW} / \mathrm{cm}^{2}$ ) and the IR analysis light beam. The absorbance change of the acrylate and eugenol double bond $(\mathrm{C}=\mathrm{C})$ peak area 
was correlated to the extent of the polymerization. The following relations can express the degree of conversion (DC): $D C(\%)=\left(A_{0}-A_{t}\right) \cdot 100 / A_{0}$, where $A_{0}$ is the initial peak area before the irradiation and At is the peak area at time $t$. The photopolymerization rate $(\mathrm{Rp})$ was calculated by the following relations: $\mathrm{Rp}=\mathrm{dDC} / \mathrm{dt}$, where $\mathrm{t}$ is the time of the irradiation.

Photoreactive formulation

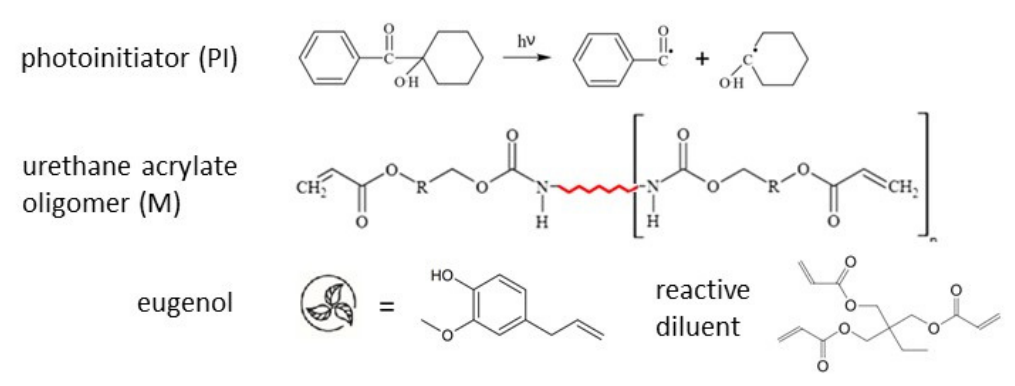

Free radical photopolymerization steps

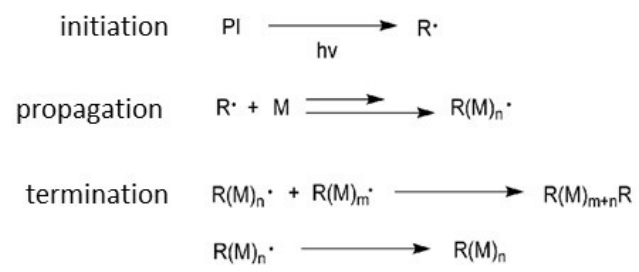

Preparation of photocurable urethane acrylate coating with antimicrobial properties
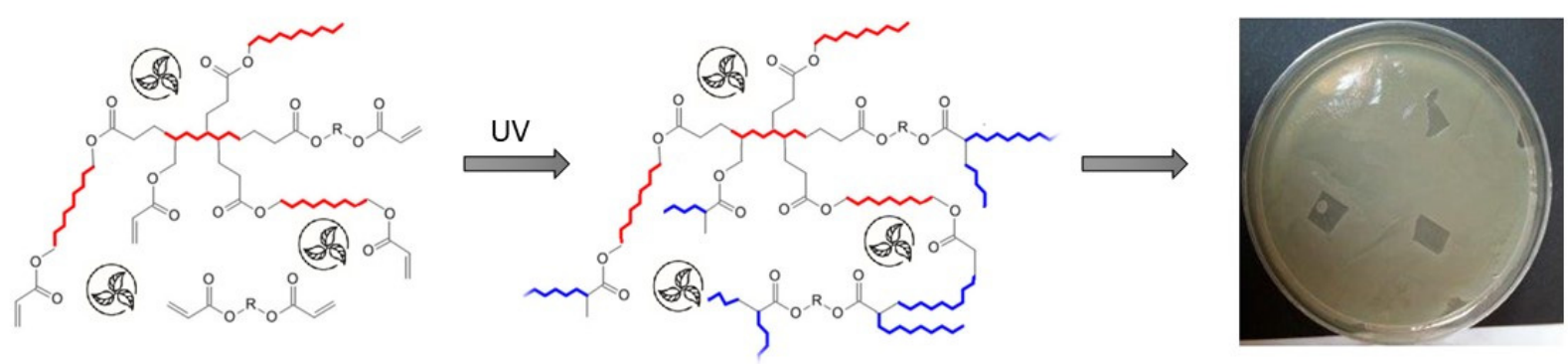

Figure 1. The method of preparing the photocurable urethane acrylate coatings containing eugenol.

\subsection{Thermal Properties}

The decomposition profile of the cured samples was thermogravimetrically analyzed using TG 209 F1 LIBRA NETZSCH (Selb, Germany) analyzer. Film samples ranging from 4 to $6 \mathrm{mg}$ were placed in the corundum sample pan and heated from 25 to $800{ }^{\circ} \mathrm{C}$, under an air atmosphere at a heating rate of $10^{\circ} \mathrm{C} / \mathrm{min}$, and the weight loss and temperature differences were recorded as the function of temperature.

\subsection{Viscosity}

The viscosity of the obtained photoreactive systems was determined with a Bohlin Visco 88 (Malvern Panalytical, Malvern, UK) viscometer. The measurement was carried out at the temperature of $20{ }^{\circ} \mathrm{C}$ using the $\mathrm{C} 14$ geometry at the speed of $20 \mathrm{rpm}$. The presented viscosity values represent the average values made from two measurements, the error of which did not exceed 3\%.

\subsection{Properties of the Cured Coatings}

The following tests were performed in order to evaluate the mechanical properties of the cured coatings: tack-free time, pendulum hardness test, adhesion, gloss, and yellowness index. Tack-free time was measured as the surface cure time according to ISO 9117. It is when the coating was deemed to be properly adhered to and achieved the final technical parameters. The presented values represent the average values made from two measurements. The hardness of coatings was tested using the König pendulum hardness tester according to ASTM D 4366 with respect to pendulum oscillation times on the coatings on the glass substrate. Hardness test was carried out after $24 \mathrm{~h}$ and after 2 months. The presented values represent the average values made from three measurements, the error 
of which did not exceed 5\%. Adhesion of the coatings to the glass substrate was measured using the pull-off adhesion tester according to the national and international standards, including ASTM D4541/D7234 and ISO 4624/16276-1. The presented values represent the average values made from seven measurements, the error of which did not exceed 10\%. Gloss was measured by spectrometer GLS (SADT Development Technology Co. Ltd., Beijing, China) according to ASTM D523. The presented values represent the average values made from three measurements, the error of which did not exceed $5 \%$. Yellowness index is the number calculated from spectrophotometric data that describes the change in color of the tested samples. This parameter was measured according to ASTM E313 and using precision colorimeter NH-145 (3NH Technology Co., Ltd., Shenzhen, China). The presented values represent the average values made from three measurements, the error of which did not exceed $5 \%$.

\subsection{Antimicrobial Properties}

The antimicrobial properties of coatings with eugenol were also examined. Test organisms used in this study were as follows: Escherichia coli strain K12 (ATCC 25922), Staphylococcus epidermidis (ATCC 49461), Candida albicans (culture isolated from immunocompromised patients). The E. coli bacteria were cultured on PCA (Plate Count Agar, BTL Poland), S. epidermidis on BHI agar (Brain Heart Infusion Agar, BTL, Łódź, Poland), Candida albicans on SDA (Sabouraud Dextrose Agar, BIOMAXIMA, Lublin, Poland). The antibacterial and antifungal properties tests of coatings based on urethane acrylates were carried out according to the European Pharmacopoeia 5.0 standards. The disc diffusion method was used.

Before the experiments, bacteria were precultured in appropriate liquid media: E. coli in Enriched Broth (BIOMAXIMA Poland) at $37^{\circ} \mathrm{C}$ and S. epidermidis in Brain Heart Infusion Broth (BTL, Poland) at $37^{\circ} \mathrm{C}$. The bacterial cultured was diluted to the final cell density 0.50 in McFarland standard (bioMérieux, Marcy l'Etoile, France), corresponding to bacterial cell number approximately $1.5 \times 10^{8} \mathrm{CFU} \mathrm{mL}{ }^{-1}$. Two-day-old yeast culture on MEA slants at $25^{\circ} \mathrm{C}$ for $\mathrm{C}$. albicans was used for preparing the yeast suspension. Sterile sodium chlorine buffer $(0.85 \% \mathrm{NaCl})$ was added to the slant, and the culture was appropriately diluted to obtain an inoculation level of appx $10^{6}-10^{7} \mathrm{CFU} \mathrm{mL}{ }^{-1}$ (corresponded to 0.55 in McFarland standard, bioMérieux, Marcy l'Etoile, France). Three hundred microliters of microbial suspension were spread on a media suitable for tested microorganism. Three samples of each varnish samples supplemented with from 1 to $10 \mathrm{wt} \%$ of eugenol were put on agar plates. A varnish without eugenol was used as a control experiment. The plates were incubated at a temperature of $37^{\circ} \mathrm{C}$ from 24 (bacteria) to $48 \mathrm{~h}$ (Candida sp.). The inhibition zone around the paper discs or lacquer samples was measured with a ruler using aCOLyte camera 7500 (Symbios, Frederick, MD, USA).

The minimum inhibitory concentration (MIC) was determined. Three sterile paper discs (Whatman No. 1, Little Chalfont, Buckinghamshire, UK diameter $5 \mathrm{~mm}$ ) were impregnated with $5 \mu \mathrm{L}$ of the suitable solution. As a solvents water, $1.0 \%$ ethyl acetate, methanol and $10 \%$ DMSO were used. The prepared solutions' concentration were as follows: $100 \%, 75 \%, 50 \%, 30 \%, 25 \%, 20 \%, 15 \%, 10 \%, 5 \%$, and $1 \%$ of eugenol. The swabbed discs were placed on the proper media. The disc swabbed with ethyl acetate solution was used as a control. The plates were incubated at the appropriate temperature $\left(37^{\circ} \mathrm{C}\right.$ for E. coli and S. epidermidis, $25^{\circ} \mathrm{C}$ for C. albicans) for $24-48 \mathrm{~h}$. The inhibition zone around the paper discs was measured with a ruler using a COLyte 7500 camera (Symbios, Frederick, MD, USA). All tests were repeated three times.

The diameter of the inhibition zones classified the sensitivity to the tested agents: not sensitive (-) for diameters less than $5 \mathrm{~mm}$; sensitive (+) for diameters 5-10 $\mathrm{mm}$; very sensitive (++) for diameters larger than $10 \mathrm{~mm}$ and less than 15 and super sensitive for diameters larger than $15 \mathrm{~mm}(+++)$. 


\section{Results and Discussion}

In this study, urethane acrylate resins were modified with eugenol in order to give them antimicrobial properties. In this studied eugenol was also used as the biologically active diluent to reduce the high viscosity. The second reactive diluent was the trifunctional acrylate monomer. The tested systems had the viscosity of $0.65 \mathrm{~Pa} \cdot \mathrm{s}$ for PRE0 to $0.61 \mathrm{~Pa} \cdot \mathrm{s}$ for PRE10.

Figure 2 shows the FTIR spectrum of eugenol and the photoreactive systems based on urethane acrylate resin before and after the modification. These systems were presented in the liquid form (i.e., before irradiation as well as after $15 \mathrm{~min}$ of the UV irradiation.

The synthesis of monomers derived from eugenol-containing polymerizable functional groups has been widely studied in recent years. The (meth)acrylation of eugenol, isoeugenol, and dihydroeugenol was performed and the solution homopolymerization of these biobased monomers was studied. Moreover, aiming to prepare functional polymers, the introduction of epoxy and cyclic carbonate groups was executed via modification of the allylic double bond present in eugenol-derived methacrylate [30]. However, it is known from the literature that phenols are strong radical scavengers. Hence, eugenol and its derivatives did not polymerize readily by the photopolymerization, as with many other bio-based monomers. Therefore, it was seen in studies present in the scientific literature that suitable functional groups are added to eugenol and its derivatives to prevent the inhibition. However, when this situation was evaluated in terms of time, energy, and waste generation, it was evident that it brings additional costs and disadvantages [31]. Polymerization studies after the modification of eugenol are frequently encountered in the literature but, in this form, they usually lose their antimicrobial properties. It is known that polymerization of pure eugenol on its own is very difficult both from the allyl group and its phenolic structure. Hence, in the FTIR spectrum of unmodified (PRE0) and modified (PRE10) resins, similar bands are observed before and after the photopolymerization process. However, a lesser extent of the disappearance of absorption peak corresponding to $C=C$ stretching vibrations developing at $809 \mathrm{~cm}^{-1}$ in the case of the modified system would suggest a lower degree of conversion of unsaturated acrylate bonds. Such conclusions can also be drawn based on real-time monitoring of the photopolymerization course using the spectroscopic method (Figure 3). For this purpose, the $\mathrm{C}=\mathrm{C}$ unsaturated bond disappearance at $809 \mathrm{~cm}^{-1}$ was measured. On the basis of the obtained data, the course of conversion and the speed of the photopolymerization during exposure to the UV radiation were determined. Based on the received data, the course of conversion and the photopolymerization rate during exposure to the UV radiation were determined. On the basis of the course of conversion and the speed of the selected systems, it was confirmed that the presence of eugenol results in a lower conversion of unsaturated bonds and slows down the photopolymerization process. Hence, it is presumed that eugenol is trapped in the structure of the polymer network and it can be trapped in the urethane acrylate shell via e.g., hydrogen bonds derived from the hydroxyl group.

During the studies, the increase in the amount of eugenol in the polymeric film decreased the hardness and increased the adhesion strength to the substrate. However, the most preferred protective coatings were those which formed a hard coating with high adhesion. It is assumed that coatings with hardness below 30 were flexible, which limits their use as the protective coatings. On the other hand, adhesion below 2 MPa may be insufficient to obtain durable coatings on a proper substrate. Therefore, the most beneficial results characterize the coating with $3 \mathrm{wt} \%$ of eugenol related to the adhesion and hardness, which is shown as the intersection of the two curves in Figure 4. 

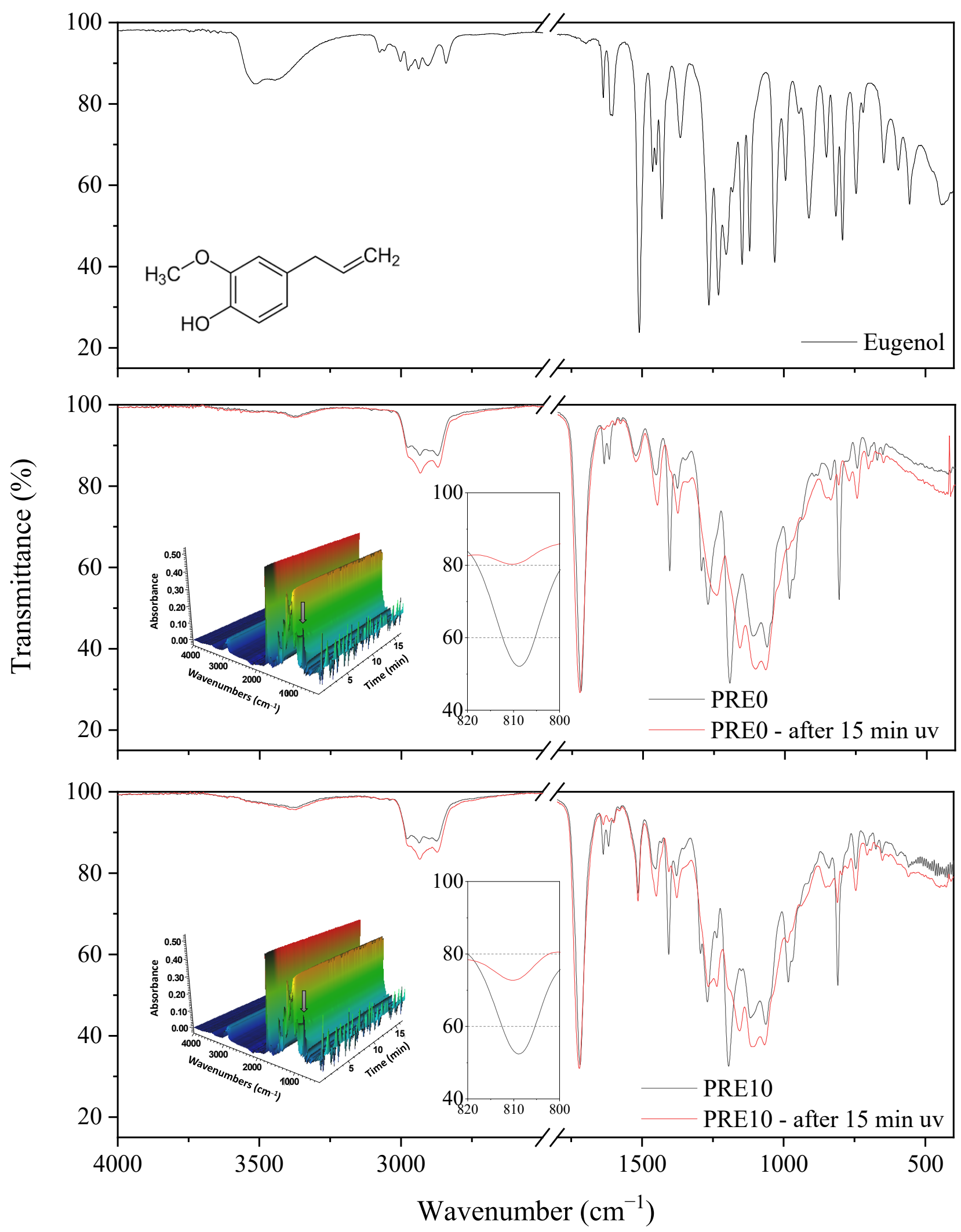

Figure 2. FTIR spectra of eugenol unmodified (PRE0) and modified (PRE10) urethane acrylate resin before and after exposure to the UV radiation. 

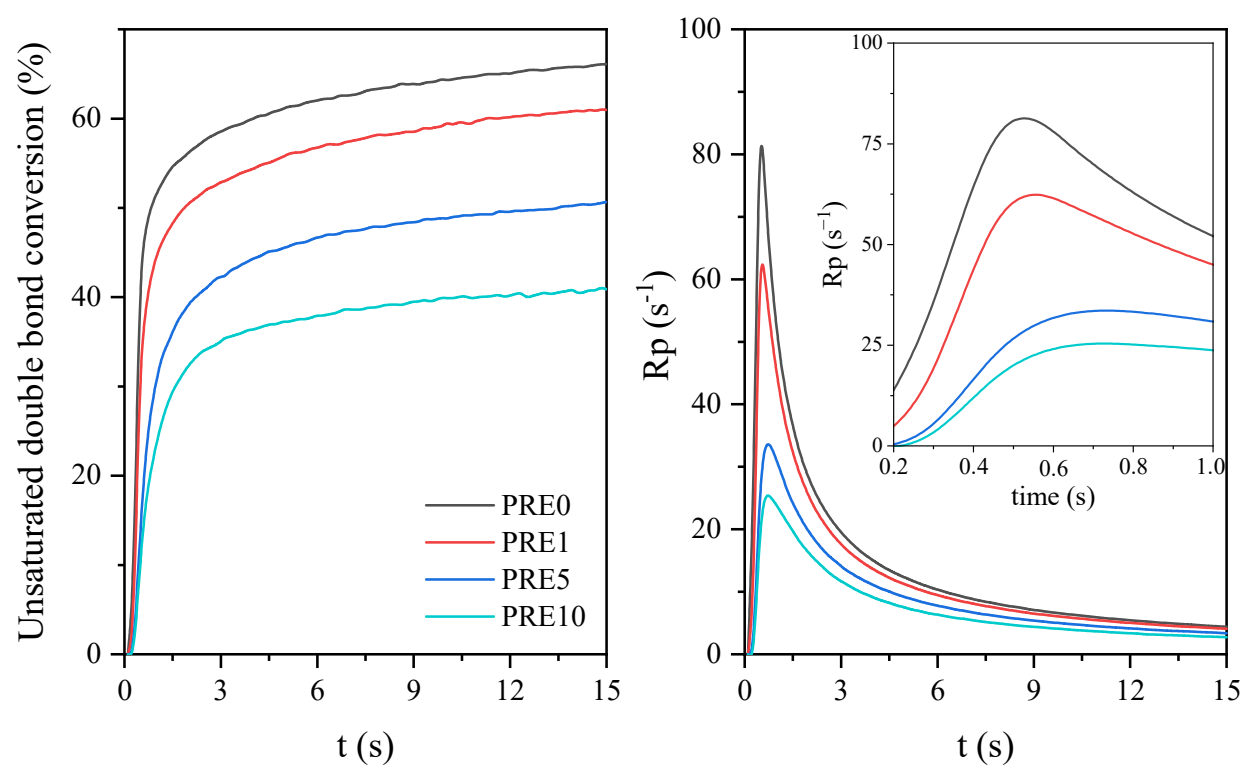

Figure 3. The unsaturated double bond conversion and photopolymerization rate (Rp) curves of selected urethane acrylate modifications with different amounts of eugenol.

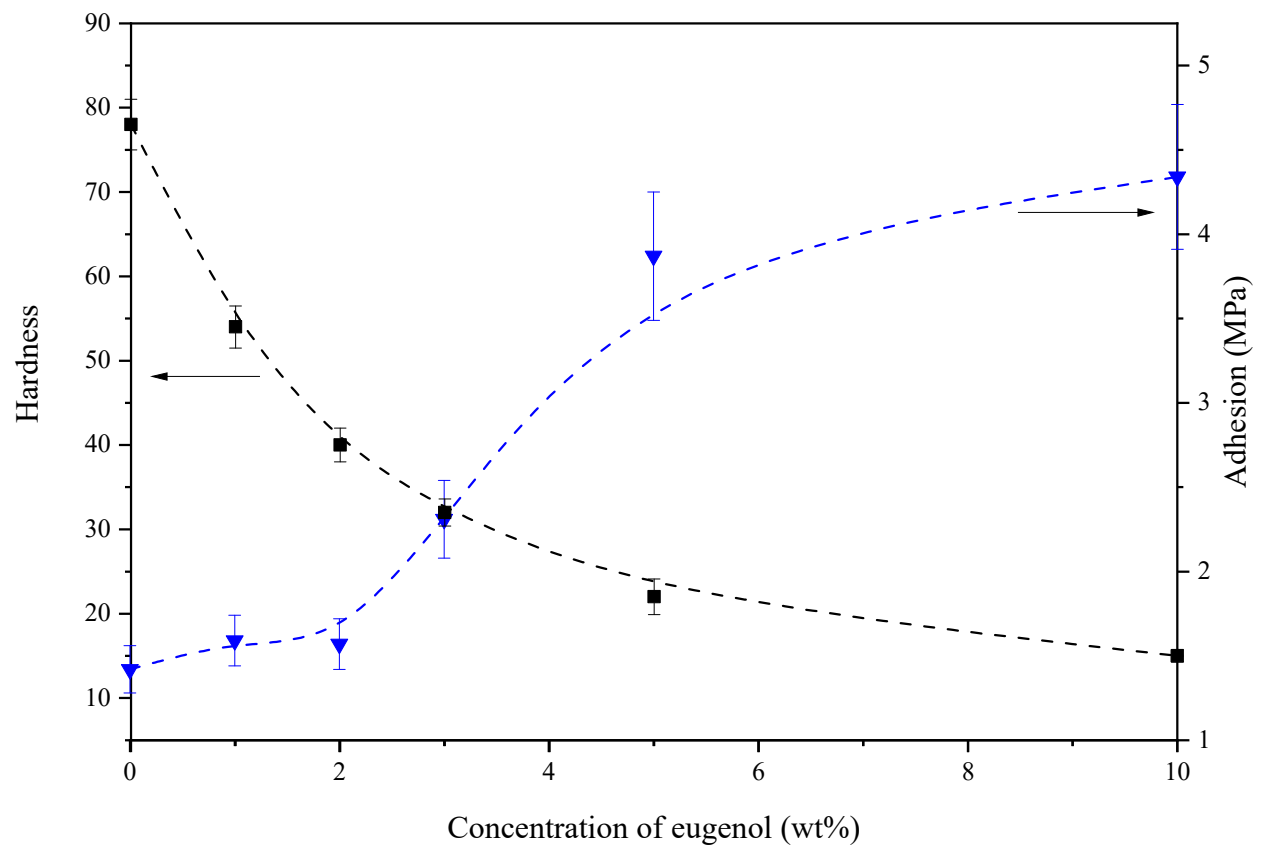

Figure 4. Pendulum hardness and adhesion of obtained UA coatings depending on eugenol concentration.

After analyzing the results, the following question arises: why did adhesion increase when eugenol was added? We can answer that eugenol can play the role of the so-called plasticizer. Without reacting chemically with other ingredients in the composition, eugenol "softens" the coating layer, increasing adhesion in a natural way. The second question is: why did surface hardness decrease when eugenol was added? On this question, we can answer that the addition of eugenol increases the adhesion and, thus, reduces the hardness of the cross-linked (hardened) coating.

The comparative analysis of the TG curves of the varnish samples with different eugenol content showed that the higher the eugenol content, the lower the stability of the samples. 
The most meaningful data from the TGA curves (i.e., the initial decomposition temperature (IDT), the temperatures at which $5 \%, 10 \%$, and $50 \%$ of the specimen decomposed thermally, and the temperature with the maximum weight loss) were collected in Table 1. The TGA curves all show three (for UV-cured urethane acrylates without eugenol) and four (for UV-cured urethane acrylates with eugenol) distinct regions of weight loss irrespective of formulation, indicating a four-stage degradation process (Figure 5). The first weight loss observed in the range of $100-150{ }^{\circ} \mathrm{C}$ is probably connected with the evaporation of TMPTA not bounded with eugenol. The decomposition temperature corresponding to $5 \%$ weight loss is from 144.8 to $214.2^{\circ} \mathrm{C}$. In Table 1, PRE 1 showed the highest thermal stability.

Table 1. Effect of eugenol content on the thermal properties of cured urethane acrylates.

\begin{tabular}{cccccc}
\hline \multirow{2}{*}{ Sample } & IDT $\left({ }^{\circ} \mathbf{C}\right)$ & \multicolumn{3}{c}{ TGA Weight Loss } & \multirow{2}{*}{ MDT ( $\left.{ }^{\circ} \mathbf{C}\right)$} \\
\cline { 3 - 5 } & & $\mathbf{T}_{\mathbf{d}}{ }^{\mathbf{5} \%}\left({ }^{\circ} \mathbf{C}\right)$ & $\mathbf{T}_{\mathbf{d}}{ }^{\mathbf{1 0} \%}\left({ }^{\circ} \mathbf{C}\right)$ & $\mathbf{T}_{\mathbf{d}}{ }^{\mathbf{5 0} \%}\left({ }^{\circ} \mathbf{C}\right)$ & \\
\hline PRE0 & 170.6 & 247.3 & 294.7 & 381.2 & $369.0(-6.87 \% / \mathrm{min})$ \\
PRE1 & 156.5 & 214.2 & 285.6 & 370.1 & $361.6(-7.16 \% / \mathrm{min})$ \\
PRE 2 & 129.5 & 192.2 & 283.3 & 369.3 & $361.5(-6.84 \% / \mathrm{min})$ \\
PRE 3 & 129.7 & 186.5 & 275.0 & 369.1 & $357.2(-6.80 \% / \mathrm{min})$ \\
PRE 4 & 127.4 & 181.6 & 270.3 & 365.1 & $357.6(-7.02 \% / \mathrm{min})$ \\
PRE 5 & 112.4 & 166.0 & 261.1 & 388.4 & $362.3(-6.65 \% / \mathrm{min})$ \\
PRE 6 & 112.6 & 169.7 & 261.2 & 368.2 & $360.1(-6.68 \% / \mathrm{min})$ \\
PRE 7 & 120.2 & 161.9 & 213.8 & 368.5 & $361.6(-6.55 \% / \mathrm{min})$ \\
PRE 9 & 118.6 & 149.6 & 188.3 & 364.3 & $369.2(-6.11 \% / \mathrm{min})$ \\
PRE 10 & 115.1 & 144.8 & 181.1 & 360.1 & $353.7(-6.28 \% / \mathrm{min})$ \\
\hline
\end{tabular}

The addition of eugenol reduces the thermal stability of the urethane acrylates varnishes. The rate of the decomposition of varnishes for the concentration of eugenol in the range of $2-6 \mathrm{wt} \%$ is similar, but for the concentrations of eugenol $7-10 \mathrm{wt} \%$, an increase in the rate of the weight loss (decomposition) is observed. The initial temperature of the decomposition for the lacquer PRE3 is amounted to approximately $130^{\circ} \mathrm{C}$, and the change in the stability is probably connected with the evaporation of the diluent and eugenol. The highest stability at the higher temperatures was observed for the varnish without eugenol and the lowest for the varnish with eugenol in amount of $10 \mathrm{wt} \%$.

At a concentration of $10 \mathrm{wt} \%$ of eugenol in the coating structure having a thickness of $1 \mathrm{~mm}$, the inhibition zone was observed, which as approximately $0.9 \mathrm{~cm}$ in diameter in the case of tests carried out on Candida albicans. In tests with bacterial cultures, it was found that coating with eugenol was not conducive to colonization because under the surface of coating, the growth of colonies was not observed. No growth of Staphylococcus epidermidis under the surface of the coating was observed even at a concentration of $1 \mathrm{wt} \%$ of eugenol, whereas in the case of Escherichia coli at the concentration of $3 \mathrm{wt} \%$ (Figure 6). It was believed that the best use of coating with eugenol as the antimicrobial coating will be their local application, especially at the interface between the coating surface with a substrate, they cause a local disappearance of fungi yeast and bacteria colonies, both Gram-negative and -positive. A moderate antimicrobial activity against E. coli, P. aeruginosa, S. aureus, and B. cereus was detected for the eugenol-rich PLA-based materials [32,33]. Our findings showed that eugenol enclosed in varnish structures has antimicrobial properties. 


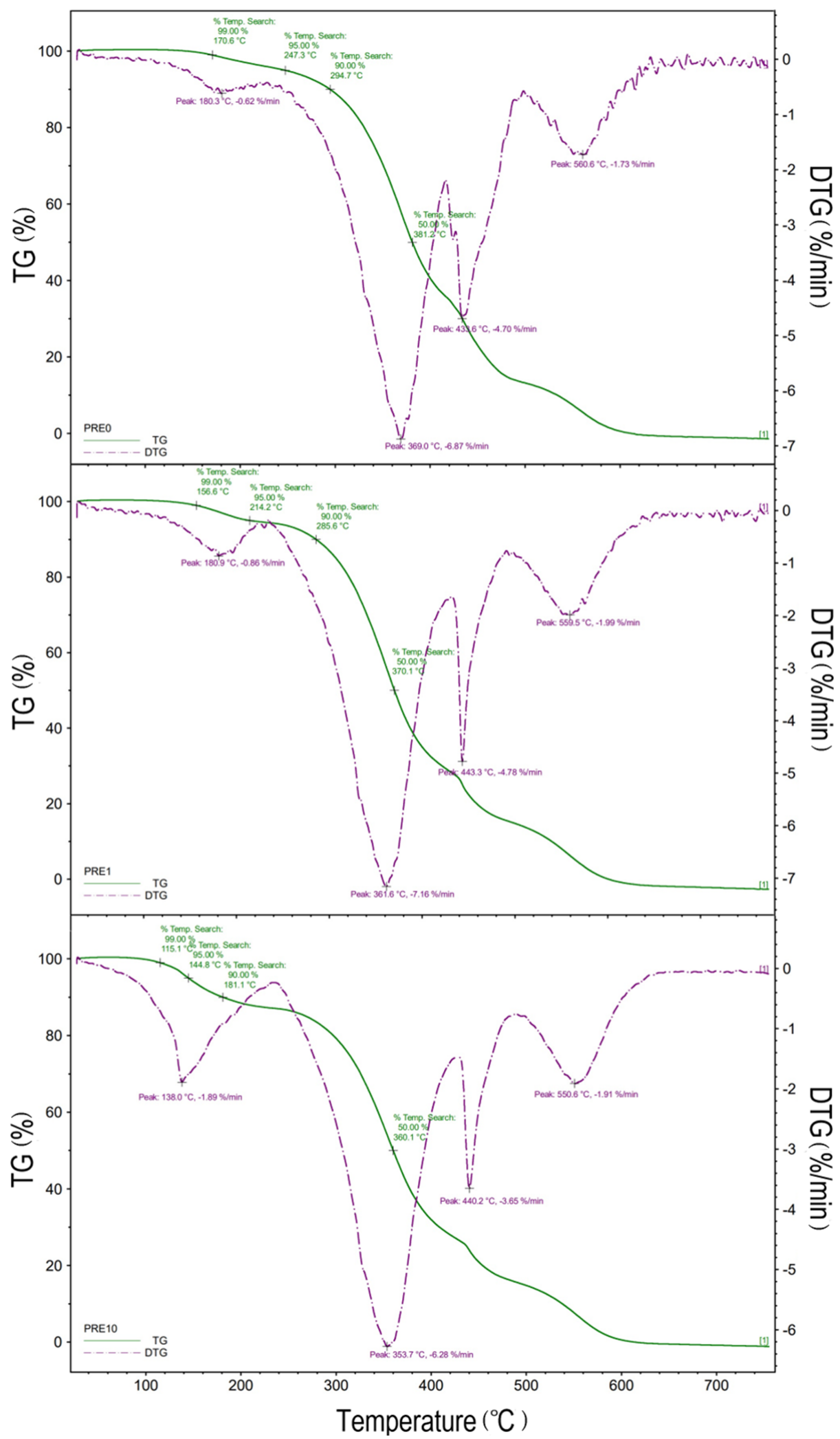

Figure 5. TGA and DTG data coatings based on urethane acrylate with different amounts of eugenol. 
C. albicans

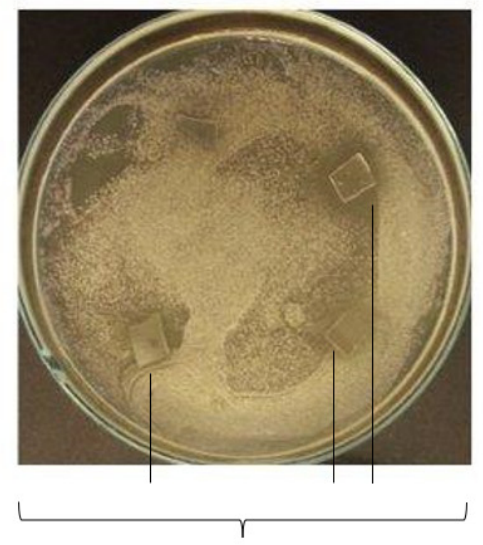

PRE10
S. epidermidis

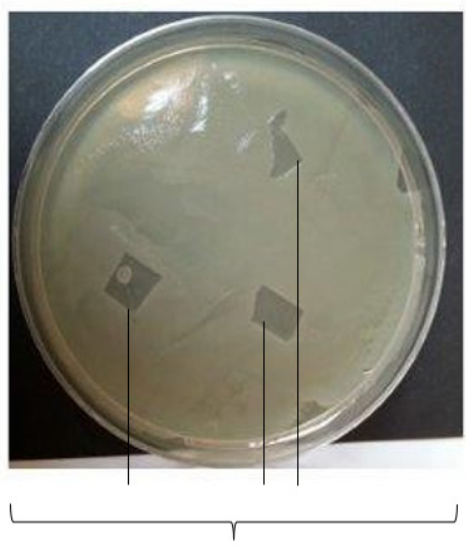

PRE1
E.coli

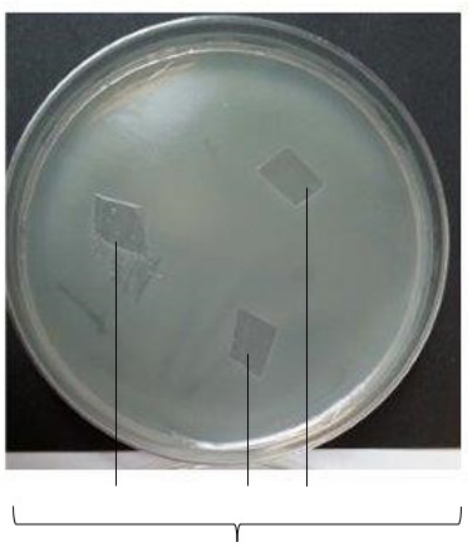

PRE3

Figure 6. The cured coatings on substrates with antimicrobials.

The size of microbial growth inhibition zones depended on the solvent used in the dissolution of eugenol. The minimum inhibitory concentration of eugenol tested as solutions with ethyl acetate is in the form of the inhibition zone of the growth of microorganisms. The results are shown in Figure 7. E. coli bacteria are sensitive to the $1 \mathrm{wt} \%$ solution of eugenol, while C. albicans and S. epidermidis have the inhibition zone for $5 \mathrm{wt} \%$ solutions. The $15 \mathrm{wt} \%$ solutions of eugenol did not significantly change the inhibition zones for all tested microorganisms. According to Nejad et al. (2017) [34] eugenol has shown an inhibitory effect on the growth of most gram-negative (Escherichia coli; Salmonella typhi; Pseudomonas aeruginosa) and gram-positive (Staphylococcus epidermidis, Streptococcus pneumoniae, and Streptococcus pyogenes) bacteria at the concentration of $1000 \mu \mathrm{g} / \mathrm{mL}$. Among known natural products extracted from clove eugenol has the lowest antimicrobial effect. However, a synergistic antibacterial activity between eugenol and other substances (natural or additives) was observed [28,35]. The mechanism of eugenol's antimicrobial action is still under discussion. It seems, however, that it induces protein, lipid leakage of cell membranes, increases the transport of potassium and ATP out of the cells, or disturbs the bacterial cell structure $[33,35]$. The antibacterial action of eugenol is most likely related to the presence of the phenol group in the eugenol molecule, which was discussed in detail in the work of Breloy et al. [36]. It is reported in this paper that phenol groups are responsible for the disruption of the bacterial membrane and that the differences in the bactericidal effect can be explained by the difference in cell-wall structures between bacteria. Gram-negative bacteria (E. coli) are protected by a thin layer of peptidoglycans and liposaccharides. Gram-positive bacteria (S. epidermidis) have cell wall consist of thicker and more protective peptidoglycans. Additionally, the surface of Gram-negative bacteria is more hydrophobic than Gram-positive ones, which favor their contact with hydrophobic surfaces. According to the research of. Breloy et al. [36] eugenol-derived coating exhibits a high hydrophobicity. Our research results are in line with these conclusions. In our work, the best results in microbiological tests were also obtained for Gram-negative bacteria (E. coli). 


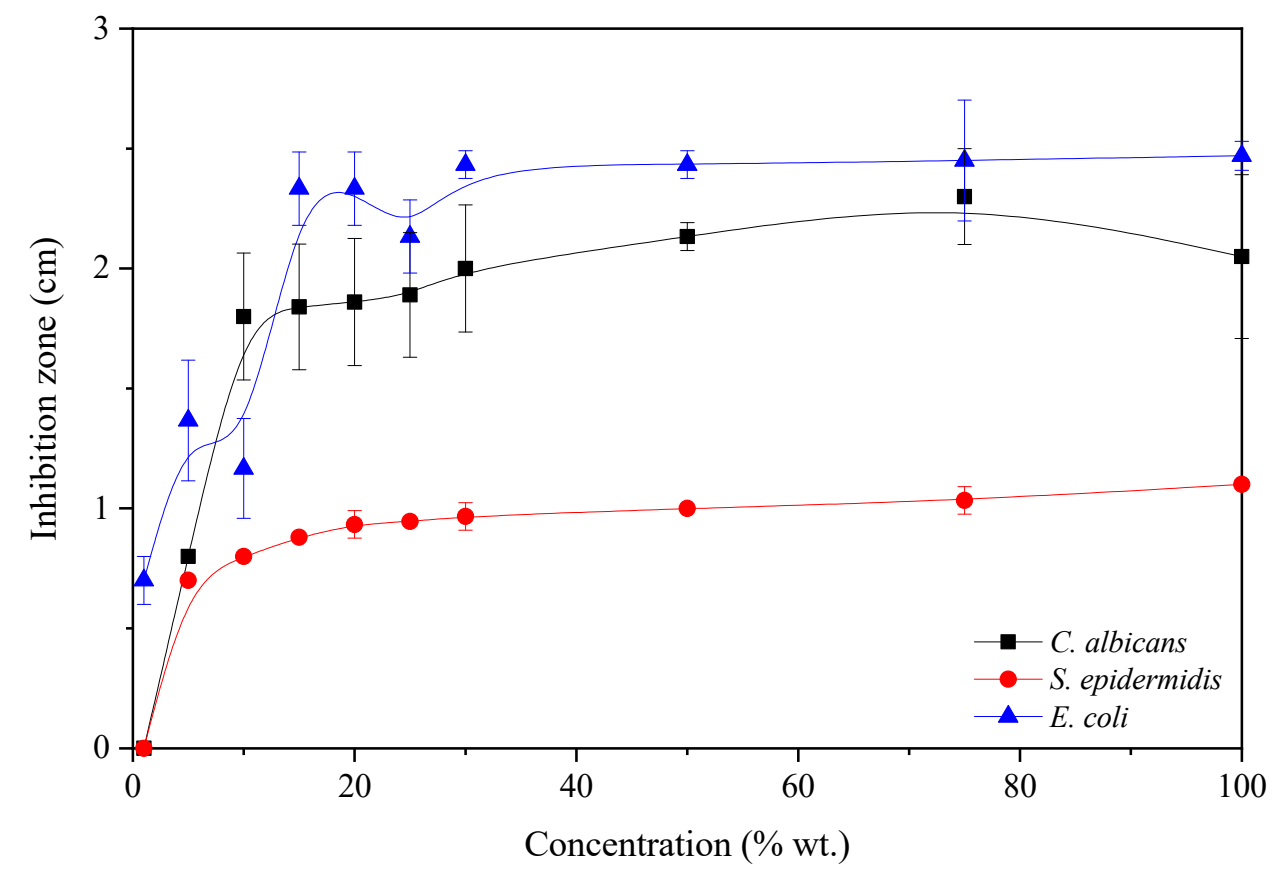

Figure 7. The impact of concentrations of the eugenol for microbial growth inhibition zone.

\section{Conclusions}

The studies showed that eugenol (a component of biomass) present in coatings was the inhibitor of the growth of the microorganism. Thus, it is possible to obtain photoreactive coatings with antimicrobial activity by the simple modification of the photoreactive resins. Due to the fact that eugenol does not undergo photopolymerization in these systems but only remains in the structure of the polymer network, it retains its antimicrobial activity. But taking into account the fact that the increase of the concentration of eugenol in the compositions of the coatings increased adhesion but reduced the hardness of the coating layers, the appropriate concentration of eugenol in compositions should be selected for the particular applications. The presented studies allowed to confirm the possibility of receiving photoreactive resins by modifying with eugenol. It opens the possibility of using the resins thus obtained in a wide range of film-forming processes for obtaining materials with antimicrobial properties.

Author Contributions: Conceptualization, P.B. and A.W.; methodology, P.B. and A.M.-S.; validation, P.B., A.W. and A.M.-S.; formal analysis, P.B., A.M.-S. and P.O.-R.; investigation, P.B., A.M.-S., P.O.-R. and M.N.; data curation, P.B.; writing-original draft preparation, P.B., A.W., A.M.-S. and P.O.-R.; writing-review and editing, P.B., A.W., A.M.-S., M.K. and A.K.; visualization, P.B.; supervision, P.B., A.W., A.M.-S. and Z.C. All authors have read and agreed to the published version of the manuscript.

Funding: The APC was funded by the Grant of Rector of the West Pomeranian University of Technology in Szczecin for PhD students of the Doctoral School, grant number: ZUT/13/2021.

Institutional Review Board Statement: Not applicable.

Informed Consent Statement: Not applicable.

Data Availability Statement: Data sharing is not applicable to this article.

Conflicts of Interest: The authors declare no conflict of interest. 


\section{References}

1. Fertier, L.; Koleilat, H.; Stemmelen, M.; Giani, O.; Joly-Duhamel, C.; Lapinte, V.; Robin, J.-J. The use of renewable feedstock in UV-curable materials-A new age for polymers and green chemistry. Prog. Polym. Sci. 2013, 38, 932-962. [CrossRef]

2. Mülhaupt, R. Green polymer chemistry and bio-based plastics: Dreams and reality. Macromol. Chem. Phys. 2013, 214, 159-174. [CrossRef]

3. Wang, F.; Hu, J.Q.; Tu, W.P. Study on microstructure of UV-curable polyurethane acrylate films. Prog. Org. Coat. 2008, 62, 245-250. [CrossRef]

4. Decker, C. Kinetic study and new applications of UV radiation curing. Macromol. Rapid Commun. 2002, 23, 1067-1093. [CrossRef]

5. Roffey, C.G. Photogeneration of Reactive Species for UV Curing; Wiley: Chichester, UK, 1997. ISBN 9780471941774.

6. Athawale, V.D.; Kulkarni, M.A. Preparation and properties of urethane/acrylate composite by emulsion polymerization technique. Prog. Org. Coat. 2009, 65, 392-400. [CrossRef]

7. Ruiz, C.S.; Machado, L.D.B.; Pino, E.S.; Sampa, M.H. Characterization of a clear coating cured by UV/EB radiation. Radiat. Phys. Chem. 2002, 63, 481-483. [CrossRef]

8. Poljanšek, I.; Fabjan, E.; Moderc, D.; Kukanja, D. The effect of free isocyanate content on properties of one component urethane adhesive. Int. J. Adhes. Adhes. 2014, 51, 87-94. [CrossRef]

9. Dzunuzovic, E.; Tasic, S.; Bozic, B.; Babic, D.; Dunjic, B. Dynamical mechanical analysis of photocrosslinked hyperbranched urethane acrylates. J. Serb. Chem. Soc. 2004, 69, 441-453. [CrossRef]

10. Dunjic, B.; Tasic, S.; Bozic, B. Hyperbranched urethane-acrylates. Eur. Coat. J. 2004, 6, 36-41.

11. Bednarczyk, P. Curing temperature of photocurable varnishes based on the urethane acryeates Temperatura utwardzania fotoutwardzalnych lakierów na bazie uretanoakrylanów. Przem. Chem. 2015, 1, 144-146. (In Polish) [CrossRef]

12. Dzunuzovic, E.; Tasic, S.; Bozic, B.; Babic, D.; Dunjic, B. UV-curable hyperbranched urethane acrylate oligomers containing soybean fatty acids. Prog. Org. Coat. 2005, 52, 136-143. [CrossRef]

13. Król, P. Synthesis methods, chemical structures and phase structures of linear polyurethanes. Properties and applications of linear polyurethanes in polyurethane elastomers, copolymers and ionomers. Prog. Mater. Sci. 2007, 52, 915-1015. [CrossRef]

14. Bai, C.Y.; Zhang, X.Y.; Dai, J.B.; Li, W.H. A new UV curable waterborne polyurethane: Effect of CC content on the film properties. Prog. Org. Coat. 2006, 55, 291-295. [CrossRef]

15. Xu, J.; Pang, W.; Shi, W. Synthesis of UV-curable organic-inorganic hybrid urethane acrylates and properties of cured films. Thin Solid Film. 2006, 514, 69-75. [CrossRef]

16. Park, M.-H.; Jang, W.; Yang, S.-J.; Shul, Y.; Han, H. Synthesis and characterization of new functional poly(urethane-imide) crosslinked networks. J. Appl. Polym. Sci. 2006, 100, 113-123. [CrossRef]

17. Glockner, P.; Jung, T.; Struck, S.; Studer, K. Radiation Curing. Coatings and Printing Inks. Technical Basics, Applications and Trouble Shooting; Vincentz Network GmbH \& Co. KG: Hannover, Germany, 2008; ISBN 978-3-86630-907-4.

18. Najafi, F.; Bakhshandeh, E.; Hadavand, B.S.; Saeb, M.R. Toward UV-curable urethane acrylate/silica hybrid coatings: Introducing urethane methacrylate trimethoxysilane (UAMS) as organic-inorganic coupling agent. Prog. Org. Coat. 2014, 77, 1957-1965. [CrossRef]

19. Kunwong, D.; Sumanochitraporn, N.; Kaewpirom, S. Curing behavior of a UV-curable coating based on urethane acrylate oligomer: The influence of reactive monomers. Songklanakarin J. Sci. Technol. 2011, 33, 201-207.

20. Król, P. Poliuretany_Przegląd 60-Letniego Rozwoju Ich Syntezy i Zastosowań. Polimery 2009, 54, 489-500. (In Polish)

21. Anwer, M.K.; Jamil, S.; Ibnouf, E.O.; Shakeel, F. Enhanced antibacterial effects of clove essential oil by nanoemulsion. J. Oleo Sci. 2014, 63, 347-354. [CrossRef]

22. Bednarczyk, P.; Wróblewska, A.; Czech, Z.; Malko, M.W.; Rozwadowski, Z.; Markowska-Szczupak, A. Preparation, properties and potential applications of a photocurable varnish with pleasant limonene smell. Pol. J. Chem. Technol. 2016, 18, 13-19. [CrossRef]

23. Pal, D.; Banerjee, S.; Mukherjee, S.; Roy, A.; Panda, C.K.; Das, S. Eugenol restricts DMBA croton oil induced skin carcinogenesis in mice: Downregulation of c-Myc and H-ras, and activation of p53 dependent apoptotic pathway. J. Dermatol. Sci. 2010, 59, 31-39. [CrossRef]

24. Manikandan, P.; Murugan, R.S.; Priyadarsini, R.V.; Vinothini, G.; Nagini, S. Eugenol induces apoptosis and inhibits invasion and angiogenesis in a rat model of gastric carcinogenesis induced by MNNG. Life Sci. 2010, 86, 936-941. [CrossRef] [PubMed]

25. Yogalakshmi, B.; Viswanathan, P.; Anuradha, C.V. Investigation of antioxidant, anti-inflammatory and DNA-protective properties of eugenol in thioacetamide-induced liver injury in rats. Toxicology 2010, 268, 204-212. [CrossRef]

26. Slameňová, D.; Horváthová, E.; Wsólová, L.; Sramkova, M.; Navarová, J. Investigation of anti-oxidative, cytotoxic, DNAdamaging and DNA-protective effects of plant volatiles eugenol and borneol in human-derived HepG2, Caco-2 and VH10 cell lines. Mutat. Res. Toxicol. Environ. Mutagen. 2009, 677, 46-52. [CrossRef] [PubMed]

27. Marchese, A.; Barbieri, R.; Coppo, E.; Orhan, I.E.; Daglia, M.; Nabavi, S.F.; Izadi, M.; Abdollahi, M.; Nabavi, S.M.; Ajami, M. Antimicrobial activity of eugenol and essential oils containing eugenol: A mechanistic viewpoint. Crit. Rev. Microbiol. 2017, 43, 668-689. [CrossRef] [PubMed]

28. Pavesi, C.; Banks, L.A.; Hudaib, T. Antifungal and antibacterial activities of eugenol and non-polar extract of Syzygium aromaticum L. J. Pharm. Sci. Res. 2018, 10, 337-339.

29. Chatterjee, D.; Bhattacharjee, P. Use of eugenol-lean clove extract as a flavoring agent and natural antioxidant in mayonnaise: Product characterization and storage study. J. Food Sci. Technol. 2015, 52, 4945-4954. [CrossRef] 
30. Molina-Gutiérrez, S.; Manseri, A.; Ladmiral, V.; Bongiovanni, R.; Caillol, S.; Lacroix-Desmazes, P. Eugenol: A Promising building block for synthesis of radically polymerizable monomers. Macromol. Chem. Phys. 2019, 220, 1900179. [CrossRef]

31. Saltan, F. Preparation of poly(eugenol-co-methyl methacrylate)/polypropylene blend by creative route approach: Structural and thermal characterization. Iran. Polym. J. 2021, 30, 1227-1236. [CrossRef]

32. Gazzotti, S.; Todisco, S.A.; Picozzi, C.; Ortenzi, M.A.; Farina, H.; Lesma, G.; Silvani, A. Eugenol-grafted aliphatic polyesters: Towards inherently antimicrobial PLA-based materials exploiting OCAs chemistry. Eur. Polym. J. 2019, 114, 369-379. [CrossRef]

33. Mak, K.-K.; Kamal, M.; Ayuba, S.; Sakirolla, R.; Kang, Y.-B.; Mohandas, K.; Balijepalli, M.; Ahmad, S.; Pichika, M. A comprehensive review on eugenol's antimicrobial properties and industry applications: A transformation from ethnomedicine to industry. Pharmacogn. Rev. 2019, 13, 1-9. [CrossRef]

34. Mohhamadi Nejad, S.; Özgüneş, H.; Başaran, N. Pharmacological and toxicological properties of eugenol. Turk. J. Pharm. Sci. 2017, 14, 201-206. [CrossRef]

35. Pei, R.; Zhou, F.; Ji, B.; Xu, J. Evaluation of combined antibacterial effects of eugenol, cinnamaldehyde, thymol, and carvacrol against E. coli with an improved method. J. Food Sci. 2009, 74, M379-M383. [CrossRef] [PubMed]

36. Breloy, L.; Ouarabi, C.A.; Brosseau, A.; Dubot, P.; Brezova, V.; Abbad Andaloussi, S.; Malval, J.-P.; Versace, D.-L. $\beta$ carotene/limonene derivatives/eugenol: Green synthesis of antibacterial coatings under visible-light exposure. ACS Sustain. Chem. Eng. 2019, 7, 19591-19604. [CrossRef] 